UNIVERSITÀ CATTOLICA DEL SACRO CUORE

Dipartimento di Economia e Finanza

\author{
Working Paper Series
}
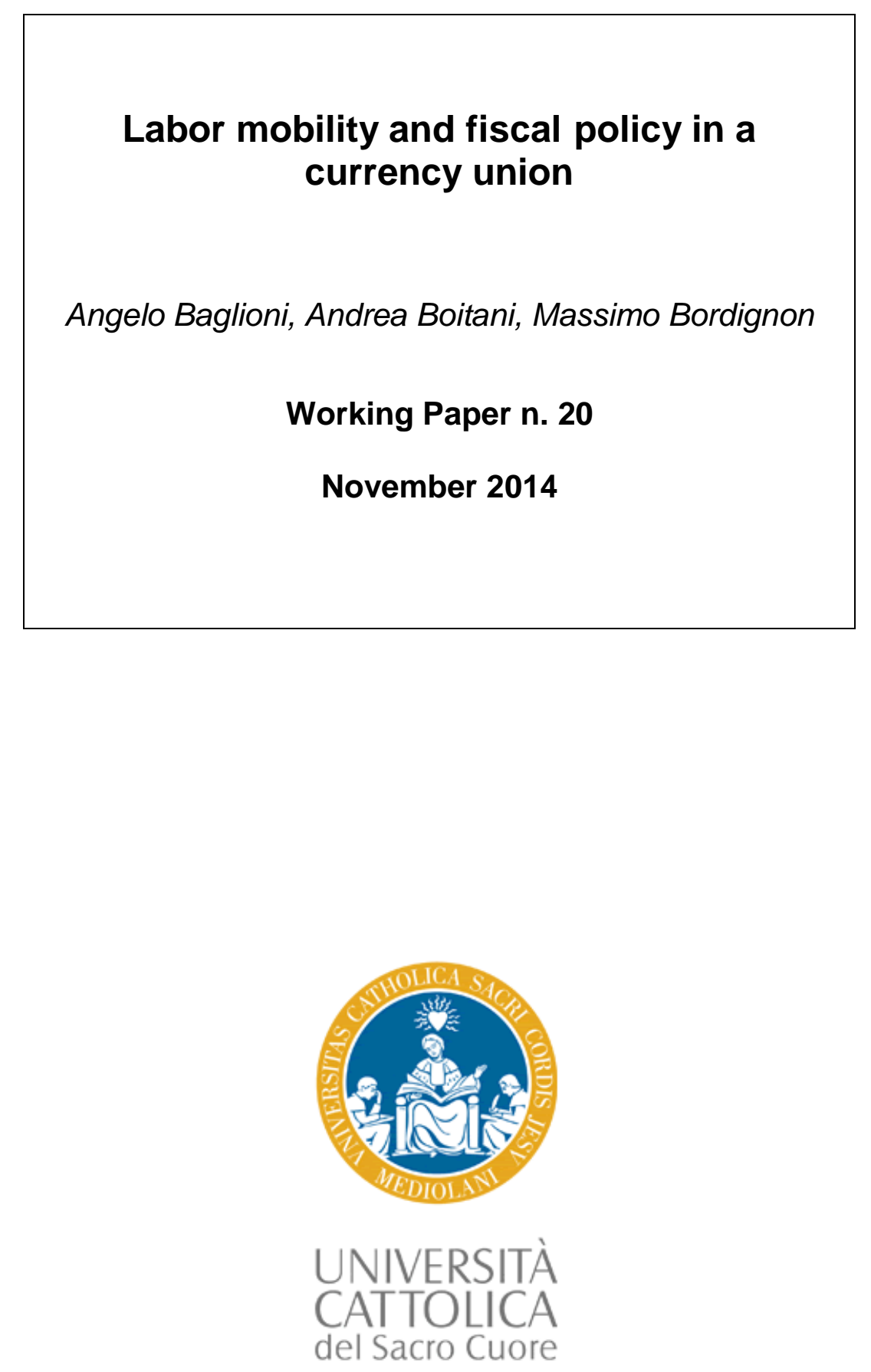


\title{
Labor mobility and fiscal policy in a currency union
}

\author{
Angelo Baglioni, Andrea Boitani, Massimo Bordignon \\ Università Cattolica del Sacro Cuore
}

Working Paper n. 20

November 2014

\author{
Dipartimento di Economia e Finanza \\ Università Cattolica del Sacro Cuore \\ Largo Gemelli 1 - 20123 Milano - Italy \\ tel: +39.02.7234.2976 - fax: +39.02.7234.2781 \\ e-mail: dip.economiaefinanza@unicatt.it
}

The Working Paper Series promotes the circulation of research results produced by the members and affiliates of the Dipartimento di Economia e Finanza, with the aim of encouraging their dissemination and discussion. Results may be in a preliminary or advanced stage. The Dipartimento di Economia e Finanza is part of the Dipartimenti e Istituti di Scienze Economiche (DISCE) of the Università Cattolica del Sacro Cuore. 


\title{
Labor mobility and fiscal policy in a currency union
}

\author{
Angelo Baglioni, Andrea Boitani, Massimo Bordignon \\ Department of Economics and Finance, Università Cattolica del Sacro \\ Cuore
}

November 2014

\begin{abstract}
Labor mobility is commonly taken as a property of an optimal currency area. But how does that property affect the outcome of fiscal policies? We address this issue with a two country - two period model, where both asymmetric and symmetric productivity shocks may hit the countries. We show that perfect (costless) labour mobility is not necessarily welfare improving, since it prevents the national fiscal authorities from pursuing independent policies, opening the way to a coordination problem between them, which is particularly relevant when the two countries differ for their intertemporal preferences. With symmetric shocks, the federal fiscal policy can improve welfare over national policies by playing a coordinating role. With asymmetric shocks, the federal fiscal policy allows both countries to reach a higher productive efficiency; to do that, the federal government must be endowed with a federal budget, playing a stronger role than plain coordination between countries.
\end{abstract}

Keywords: currency union, labor mobility, fiscal policy, federation.

JEL codes: E62, H77.

We wish to thank for their very helpful comments the discussants and audience at CESifo-Delphi Conference 2011, IIPF Conference in Taormina 2013, and seminars at the Catholic University of Milan, Free University of Berlin, WZB Berlin and the Friedrich-Alexander University of Erlangen-Nürnberg. 


\section{Introduction}

Is (geographic) labor mobility an essential component of an optimal currency union? Since Mundell's (1961) seminal work on optimal currency area, most economists would emphatically answer yes. Mundell noted that a currency union eliminates exchange rate flexibility as a way of responding to asymmetric regional real shocks; labour mobility, by allowing workers to move from regions hit by a negative shock to regions hit by a positive one, could then work as a substitute. It then follows that a currency union without, or with not enough, labor mobility across countries or regions is deemed to fail. This view is pervasive. For instance, at the time of the introduction of the Euro, several US economists, comparing the US with the EU, criticized the European Monetary Union (EMU), precisely because this area did not satisfy the labor mobility requirement ${ }^{1}$. Other puzzling features of the EMU, such as the lack of a federal budget or even of a federal government, did at the time raise less concern.

However, Mundell's argument was developed without considering the role of fiscal policy and of its institutions, a point that was made as early as 1969 by Peter Kenen ${ }^{2}$. Furthermore, Mundell's analysis is static, he did not consider the problems that mobility may create in an intertemporal setting. Adding these two elements might change the results. Suppose for instance that fiscal policy has some beneficial effects, say because Ricardian equivalence does not hold. Then public debt (and counter-cyclical fiscal policy) might play a positive role, for instance allowing a government to smooth private consumption across periods in response to a shock. But suppose this government is now a regional government, member of a currency union, and that this union is characterized by perfect labor mobility, as wished by the optimal currency area literature. Then, labor mobility - and in general, any kind of factor mobility- may have also some negative effects. This is because people leaving a region or a country are no longer viable to income taxation in the country of origin. But then, if workers can leave freely in each period the region, there may simply be no enough tax base or people left to pay for the government debt; the regional government may then be forced to redeem

\footnotetext{
${ }^{1}$ For a broad survey of US economists opinion on the EMU prior to 2002, see Jonung and Drea (2009).

2 "Fiscal and monetary policy must go hand in hand, and if there is to be an 'optimum policy mix', they should have the same domains. There should be a treasury, empowered to tax and spend, opposite each central bank" (Kenen, 1969: 45-46)
} 
its debt ${ }^{3}$. Alternatively, if agents and markets correctly anticipate this potential negative effect of labor mobility on future public revenues, the regional government might not be able to raise the desired resources to start with, so being forced to follow a sub-optimal fiscal policy. Thus, labor mobility might constraint dynamic fiscal policy; and this might be bad for citizens as long as the regional government fiscal policy is welfare enhancing. Notice in contrast that a federal government, that is, a common government for the currency area as a whole, would not have this problem, as it could still raise taxes on individuals wherever they decided to locate in the federation ${ }^{4}$. This would then suggest that even in the presence of full labor mobility, the potential advantages of a currency union could not be obtained without a federal government and a federal budget. Labor mobility and a federal budget should then be both elements of a well functioning currency union.

In the following, we set up a very simple model in order to make this intuition precise. In the model, there are two periods and two regional welfare maximizing governments, members of a currency union, that might be subject to a temporary productivity shock in the first period. The two governments may then wish to use fiscal policy (labor tax and transfers) in order to smooth private consumption across the two periods. For simplicity, we assume that public debt is always repaid, so ruling out the possibility of government bankruptcy. We first show that if the first period shock is symmetric across regions, regional labor mobility can only be damaging. By definition, in this case regional labor mobility could not generate efficiency or insurance gains, but it might force the governments to follow an inefficient intertemporal fiscal plan. Intuitively, regional governments would have to compete between them in order to attract or retain the mobile workers, so leading to inefficient fiscal choices. A federation in this case could help, by playing a coordination role, but the optimal policy would be in this case to forbid labor mobility altogether.

On the contrary, if the shock is asymmetric across regions, labor mobility plays an important insurance and efficiency role, as correctly predicted by

\footnotetext{
${ }^{3}$ The recent case of Detroit, that lost half of the population in a decade and was then forced to bankrupt, comes naturally to mind.

${ }^{4}$ The federation would of course still have problems in taxing capital income, if this is mobile across federations, as suggested by a huge literature on tax competition. But it is a characteristic of labor income to be earned in the location where the individual works; it is generally impossible to move around labor without also moving the individual who supplies this labor.
} 
Mundell (1961). Still, we show that even in this case, competition among governments leads to inefficient level of mobility, thus making it impossible for the two countries to reap all the potential benefits in terms of increased output. Furthermore, while private consumption is equalized across regions in each period, thus providing full insurance to workers, the intertemporal path of consumption across periods is not the same the welfare maximizing governments would have chosen in the absence of mobility and with the extra resources generated by mobility. The solution is clearly not to reduce efficiency enhancing mobility but to reduce the competition across regional governments, a role that could only be played by a federal government. Indeed, we show that in the case of asymmetric shocks the ability of the federation to impose federal labor taxes (and not just the federation potential coordinanting role) is essential in order to generate Pareto improvements. Thus, interestingly, our results suggest that a federal budget is needed exactly when labor mobility is mostly useful.

The literature related to the present paper is huge. For instance, Sala-iMartin and Sachs (1991) already suggested that contrary to Mundell's (1961) claim, in the US it is mainly the fiscal federalist system of taxes and transfers, and not labor mobility, that absorbs most of the asymmetric shocks across states, an extimation later revised and made more precise by von Hagen (1992) and others (see Kletzer and von Hagen 2001 for a survey). In Europe, before the introduction of the EMU, there was a large debate on the need to accompany the monetary union with a federal budget (e.g. the MacDougall - E.C. Commission Report, 1977 and the Delors' Report, 1989), building up on the original Kenen's arguments. But as it is well known the Maastricht Treaty (signed in 1991 to pave the road to the monetary union) did not consider a federal fiscal budget as a prerequisite for a monetary union and indeed imposed constraints on the fiscal policy of member countries (Sapir, 2008).

On more theoretical grounds, the role of federal fiscal policies in absorbing asymmetric shocks in a monetary union has already been discussed by a large academic literature (Kletzer, Buiter, 1997; Kletzer, 1999; Kletzer, von Hagen, 2001; Evers, 2006). Some work also focused on more specific issues - such as unemployment insurance and tax revenue sharing in Europe (von Hagen and Wyplosz, 2008) - or at evaluating whether a federal fiscal policy is stabilizing or is likely to increase the correlation among shocks (Belke and Gros, 2009a, 2009b). Finally Bofinger and Mayer (2007) already made the point that national fiscal policies are needed in order to absorb demand and/or supply 
shocks in the absence of federal fiscal insurance. However, none of these works discuss labour mobility in details; consequently, the interplay between labour mobility and fiscal policy that is the focus of the present paper is largely ignored.

The rest of the paper is organized as follows. Section 2 lays out the basic framework of our model. Section 3 analyzes the interplay between perfect (costless) labour mobility and fiscal policy (national and federal) in the case of symmetric shocks. Section 4 replicates the same analysis for asymmetric shocks. In section 5 we discuss, among others, the extension to the case of imperfect (costly) mobility. Section 6 further comments on our findings. All proofs of the propositions are in Appendix 1. Appendix 2 provides some further results and it discusses some technical problems.

\section{The model}

In order to make our point as neatly as possible, we will consider here the simplest possible setting that allows us to develop our analysis. Consider then an economy with 2 countries (regions): $i=A, B, 2$ periods: 1,2 (lower (UPPER) case will stand for first (second) period variables from now on) and 2 states of nature: $s=\alpha, \beta$, each occurring with probability $1 / 2,1 / 2$. In each country, there are $N$ workers/consumers, who are all characterized by the same utility function

$$
U^{i}=\ln (c)+\delta_{i} \ln (C)
$$

where $c$ (resp. $C$ ) represents workers' private consumption in the first (resp. second) period, and $\delta_{i}$ is the discount factor. Each worker is endowed with one unit of labour in each period that is inelastically supplied. In each country, production combines labour with some fixed factors of production in order to produce an homogenous good, according to the production function

(02) $y_{i s}=\theta_{i s} l_{i}^{\gamma} ; Y_{i}=\Theta L_{i}^{\gamma}$

where $l_{i}$ (resp. $L_{i}$ ) is the number of workers employed in the production of good $y_{i}$ (resp. $Y_{i}$ ) in country $i$ in the first (resp. second) period, and $\gamma$ lies in the interval $0<\gamma<1$, implying decreasing returns to labour. $\theta_{i s}$ and $\Theta$ are some positive constant. The output price is normalized to 1 . As shown in (02), production in the first period is subject to a productivity shock that depends on the state of the world. In particular, we assume that in the first period, depending on the realization of $s$, the productivity parameter $\theta$ in region $i$ may take either value $\underline{\theta}$ or $\bar{\theta}$ with probability $1 / 2$, where 
(03) $\underline{\theta}=\Theta(1-\varepsilon)$ and $\bar{\theta}=\Theta(1+\varepsilon)$, with $1>\varepsilon>0$

Notice that in line with Mundell's argument, this formulation implies that the first period shock is temporary; it disappears in the second. The presence of the shock induces some variance in wages and therefore in consumption in the two periods that is costly for workers/consumers, as their utility function is concave. Consumers may then wish to insure themselves against the occurrence of the shock. For convenience, we however assume that private citizens cannot save and have no access to capital markets: this is the simplest way of incorporating the imperfections of capital markets into our model. On the contrary, we assume that the national and federal governments can lend or borrow on international capital markets at some fixed interest rate $r$. Hence, there is here a valuable role for fiscal policy, as governments can use this power to insure their citizens against the shock, for instance taxing workers in the good periods and subsidising them in bad ones. In particular, we indicate with $t_{i s}$ and $T_{i s}$ the per capita lump sum government subsidies (if $>0$ ) or taxes (if $<0$ ) imposed in resp. period 1 and 2 in country $i$ on labor income ${ }^{5}$.

Notice that as workers do not own the fixed factor and have no access to capital markets, their consumption in each period must just be equal to their labor income plus the tax/transfer; that is, $c_{i s}=w_{i s}+t_{i s}$ and $C_{i s}=W_{i s}+T_{i s}$, where $w_{i s}$ and $W_{i s}$ indicate the wage received by each worker in each period in region $i$. For simplicity, as our focus here is on labor markets and labor income taxation, we ignore the returns to the fix factor (and its owners), which with perfect competitive markets are just in each period $(1-\gamma)$ times the output; we might simply assume that these returns are completely taxed away by the governments in order to finance other un-modelled components of public expenditure, say a public good that enters separately in the utility function of consumers ${ }^{6}$. Note that this entails that the intertemporal budget constraint of governments requires the taxes (subsidies) raised in the second period on labor income must be enough to finance the subsidies (taxes) paid in the first period on labor income, plus the payment (the receipt) of interests.

\footnotetext{
${ }^{5}$ As labor supply is fixed, there is no loss of generality in assuming here that all taxes or subsidies are lump sum.

${ }^{6}$ As can be easily checked, taxing the fix factor returns in order to finance subsidies to workers would not change qualitatively our results, as the returns to the fixed factor also depend on the productivity shock and on workers mobility via the output level. But adding them to the picture would also raise the question of who are the owners of this factor and their political representation, adding unnecessary complications to the discussion.
} 
We have yet to define what a government is. In the following, we will consider several possible definitions of "government". We will talk of national (regional) governments (and national policy) when decisions about $t_{i s}$ and $T_{\text {is }}$ are only taken by the government in country $i$. We will talk of a federal government, when the same decisions are taken by a federal unit. In particular, we will consider two possible federal arrangements. (i) Weak federation (coordination): the federal government chooses local taxes, but each country's intertemporal budget constraint must clear. (ii) Strong federation (federal budget): the federal government chooses local taxes and the aggregate intertemporal budget constraint must clear. The basic difference is that only the second arrangement (implicitly) allows for transfers across countries; the first just assumes that national governments can bargain among themselves and commit to Pareto efficient agreements, that we simply model here by saying that decisions are in this case directly taken by a benevolent federal government that therefore takes into account the welfare of both countries ${ }^{7}$. In all cases, we assume that governments are just social welfare maximizers; i.e. in different forms, they just wish to maximize the utility function of workers/consumers in (01).

The time line of the model is the following:

At the beginning of period 1, nature chooses $s$. Depending on who is in charge, if a federal or a national government, decisions are then taken about the tax (subsidy) $t_{i s}$. Workers observe the realization of $s$ and the tax (subsidy) chosen in both countries in period 1 , and if mobility across countries is allowed, they then move in order to maximize their utility. Labor markets then clear in both countries and the clearing markets gross wage $w_{\text {is }}$ are determined.

At period 2, the shock disappears. Governments sets again a tax (subsidy) $T_{i s}$ in order to repay the debt raised in the first period or redidistribute the interested earned in the first period by saving and investing in the capital market. Again, workers observe these moves and decide whether moving across countries; labour markets then clear and equilibrium gross wages $W_{\text {is }}$ are set in each country. The game ends here.

Notice that when labor is costlessy mobile across countries in both periods, workers will have an incentive to move in each period until per capita

\footnotetext{
${ }^{7}$ Thus, loosely speaking, we can think of the weak federation, as characterizing a union such as the EU or the EMU, where intergovernmental transfers either do not exist or are very small. The US (or most nations with their own currency) could instead be taken as examples of a strong federation.
} 
private consumption (wages net of taxes and subsidies) is equalized in each country. In this sense, then, perfect labor mobility makes workers myopic; they do not need to plan for the future because as the future comes they can always move elsewhere. Governments instead need to plan intertemporally, because by definition, they cannot move.

In the following, we will solve the model by finding the equilibrium of the game for different hypotheses about mobility costs and for different type of government. An equilibrium is defined here as a situation where: (i) labour markets clear in both periods and in both countries; (ii) workers move across countries in each period in order to maximize their utility, depending on mobility costs; (iii) each government sets $t_{i s}$ and $T_{i s}$ optimally, by maximizing its utility function (see below), and (iv) the intertemporal budget constraint of the public sector is satisfied (e.g. we rule out bankruptcy).

Clearly, under national fiscal policy, an equilibrium is just a Nash equilibrium in the tax rates $t_{i s}$ between the two countries, as $T_{i s}$ are determined residually in order to satisfy the intertemporal national budget.

\section{Symmetric shocks}

We begin by considering the case where the productivity shock is symmetric: the state $\alpha$ is bad and the state $\beta$ is good in both countries $A$ and $B$ :

\begin{tabular}{|c|c|c|}
\hline & $\alpha$ & $\beta$ \\
\hline$A$ & $\underline{\theta}$ & $\bar{\theta}$ \\
\hline$B$ & $\underline{\theta}$ & $\bar{\theta}$ \\
\hline
\end{tabular}

In this case, labor mobility does not allow the two countries to get any efficiency gain, since there is no productivity differential between them. Hence, mobility can only be either useless or damaging. Still, it is important to study in detail this simpler case first, since, as we will show, its insights largely extend to more complicated settings.

\subsection{National fiscal policies without labour mobility}

As a benchmark case, let us begin by analyzing the outcome achieved by national fiscal policies when no labour mobility across countries is allowed. Without labor mobility, the supply of labour is $N$ in both countries and in 
both periods. Moreover, the demand for labour is a function of the gross wages. Solving the model backwards, we begin by deriving the clearing conditions for the labor market in the two periods. We assume perfectly competitive markets.

Period 2. The production function is $Y=\Theta L^{\gamma}$ in both countries. In each country the labour supply is $L^{S}=N$, so the number of people employed is equal to $N$.

The firm profit maximization problem is:

$$
\max _{L} Y-W L
$$

and the FOC is:

$$
W=\Theta \gamma L^{\gamma-1}
$$

so the labour demand function in each country is:

$$
L^{D}=\left(\frac{\Theta \gamma}{W}\right)^{\frac{1}{1-\gamma}}
$$

The equilibrium condition $L^{S}=L^{D}$ determines the equilibrium wage:

$$
W^{*}=\Theta \gamma N^{\gamma-1}
$$

Period 1. Again, in each country the labour supply is $l^{S}=N$.

Let us consider country $A$. In state $\alpha$, the production function is $y_{A \alpha}=$ $\underline{\theta} l^{\gamma}$; firm profit maximization leads to:

$$
l_{A \alpha}^{D}=\left(\frac{\underline{\theta} \gamma}{w_{A \alpha}}\right)^{\frac{1}{1-\gamma}}
$$

and the equilibrium wage is:

$$
w_{A \alpha}=\underline{\theta} \gamma N^{\gamma-1} \equiv \underline{w}
$$

In state $\beta$, the same procedure leads to:

$$
w_{A \beta}=\bar{\theta} \gamma N^{\gamma-1} \equiv \bar{w}
$$

The same applies to country $B: w_{B \alpha}=\underline{w}$ and $w_{B \beta}=\bar{w}$. 
Because the shock changes the time profile of wages and this is costly for the risk adverse workers, national governments may wish to insure their consumers. They do so by setting a tax profile in their own countries, by maximizing the representative consumer utility function (01), subject to the intertemporal budget constraints:

$$
t_{i s}(1+r)+T_{i s}=0 \text { for } i=A, B \text { and } s=\alpha, \beta
$$

where $r$ is the interest rate paid (or received) in the international markets. In state $s=\alpha$, substituting the budget constraint in the objective function, the governments' problem can be written as:

$$
\max _{t_{i \alpha}} \ln \left(\underline{w}+t_{i \alpha}\right)+\delta_{i} \ln \left[W^{*}-t_{i \alpha}(1+r)\right] \quad \text { for } i=A, B
$$

solving, we get the standard Euler equation ${ }^{8}$ :

$$
\frac{C_{i \alpha}^{*}}{c_{i \alpha}^{*}}=\delta_{i}(1+r) \quad \text { for } i=A, B
$$

where $C_{i \alpha}^{*}=W^{*}-t_{i \alpha}^{*}(1+r)$ and $c_{i \alpha}^{*}=\underline{w}+t_{i \alpha}^{*}$. This condition can be solved for $t_{i \alpha}^{*}$ :

$$
t_{i \alpha}^{*}=\frac{W^{*}-\underline{w} \delta_{i}(1+r)}{\left(1+\delta_{i}\right)(1+r)} \quad \text { for } i=A, B
$$

In state $s=\beta$, the government's problem is the same as problem (9), with $\bar{w}$ replacing $\underline{w}$. Accordingly, the optimal tax rate is

$$
t_{i \beta}^{*}=\frac{W^{*}-\bar{w} \delta_{i}(1+r)}{\left(1+\delta_{i}\right)(1+r)} \quad \text { for } i=A, B
$$

Notice that the consumption vector $c_{i s}^{*}, C_{i s}^{*}$ is Pareto efficient, since it solves the optimal consumption smoothing problem of the representative agent (in each country/state of the world).

\subsection{The labour market with perfect labour mobility}

Let us then introduce costless labour mobility. When labor mobility is allowed, the number of workers in each country might of course no longer be

\footnotetext{
${ }^{8} \mathrm{SOC}$ are automatically respected as the utility function is strictly concave.
} 
equal to $N$. As a matter of notation, we then let $m$ (resp. $M$ ) be the number of workers moving in the first period (resp. second), with the convention that $m$ (resp. $M)>0$ if people move from $A$ to $B$ in the first period (resp. second) and $m$ (resp. $M)<0$ if people move from $B$ to $A$ in the first period (resp. second). Before analyzing the behavior of the fiscal authorities in this environment, we have to identify the equilibrium conditions in the labor market, taking momentarily fiscal policy as given. We focus on state $s=\alpha$; similar considerations apply to the other state of nature.

Period 2. The following system of conditions determine the equilibrium values of the gross wages and the number of people moving across countries $(M)$, taking as given the tax/subsidy rates and the number of people that has already moved in period $1(\mathrm{~m})$ :

$$
\begin{aligned}
& \left(\frac{\Theta \gamma}{W_{A \alpha}}\right)^{\frac{1}{1-\gamma}}=N-m-M \\
& \left(\frac{\Theta \gamma}{W_{B \alpha}}\right)^{\frac{1}{1-\gamma}}=N+m+M \\
& W_{A \alpha}+T_{A \alpha}=W_{B \alpha}+T_{B \alpha}
\end{aligned}
$$

where in the first two lines the demand for labour is equated to labour supply in each country; note that labour demand is a function of gross wages. The third line is due to the perfect labor mobility: as mobility is costless, people move until any net wage differential between the two countries vanishes. By solving the first two equations we get:

$$
\begin{aligned}
& W_{A \alpha}=\Theta \gamma(N-m-M)^{\gamma-1} \\
& W_{B \alpha}=\Theta \gamma(N+m+M)^{\gamma-1}
\end{aligned}
$$

which can be substituted into the third one to get:

$$
\Theta \gamma\left[(N-m-M)^{\gamma-1}-(N+m+M)^{\gamma-1}\right]+T_{A \alpha}-T_{B \alpha}=0
$$

This equation implicitly defines the equilibrium number of people that move in the second period, $M$, as a function of the two tax/subsidy rates in the second period $T_{A \alpha}$ and $T_{B \alpha}$, and on the number of people that have moved already in period $1, m$. 
Period 1. By the same token, the equilibrium values of the gross wages and the number of people moving across countries in the first period, taking as given the tax/subsidy rates, are given by:

$$
\begin{gathered}
\left(\frac{\underline{\theta} \gamma}{w_{A \alpha}}\right)^{\frac{1}{1-\gamma}}=N-m \\
\left(\frac{\underline{\theta} \gamma}{w_{B \alpha}}\right)^{\frac{1}{1-\gamma}}=N+m \\
w_{A \alpha}+t_{A \alpha}=w_{B \alpha}+t_{B \alpha}
\end{gathered}
$$

Again, by solving the first two equations we get:

$$
\begin{aligned}
& w_{A \alpha}=\underline{\theta} \gamma(N-m)^{\gamma-1} \\
& w_{B \alpha}=\underline{\theta} \gamma(N+m)^{\gamma-1}
\end{aligned}
$$

which can be substituted into the third one to get:

$$
\underline{\theta} \gamma\left[(N-m)^{\gamma-1}-(N+m)^{\gamma-1}\right]+t_{A \alpha}-t_{B \alpha}=0
$$

This equation defines implicitly the equilibrium number of people moving in the first period, $m$, as a function of the two tax/subsidy rates $t_{A \alpha}$ and $t_{B \alpha}$.

By using this last set of equations, it is an easy matter to establish a few interesting comparative statics results. Let $m=m\left(t_{A \alpha} ; t_{B \alpha}\right)$ be the number of people who moves in the first period, as derived by the arbitrage condition above. Then, we can prove (see Appendix 1):

Proposition 1 i. $\partial m / \partial t_{A \alpha}<0$; ii. $\partial m / \partial t_{B \alpha}=-\partial m / \partial t_{A \alpha}>0 ; i i i . \frac{d w_{A \alpha}}{d t_{A \alpha}}=$ $-\frac{1}{1+k}<0 ; \quad i v \cdot \frac{d c_{A \alpha}}{d t_{A \alpha}}=\frac{k}{1+k}>0, \quad v . \quad \frac{d w_{B \alpha}}{d t_{A \alpha}}=\frac{d c_{B \alpha}}{d t_{A \alpha}}=\frac{k}{1+k}>0$, vi. $\frac{d c_{B \alpha}}{d t_{B \alpha}}=$ $\frac{d c_{A \alpha}}{d t_{B \alpha}}=\frac{1}{1+k}$, where $k \equiv\left(\frac{N+m}{N-m}\right)^{\gamma-2}>0$.

The proposition illustrates neatly the effect of perfect mobility in the first period. If country $A$ raises his transfer in the first period (while $B$ keeps its transfer unchanged), it attracts more people from (or has less people moving to) country $B$; as an effect, the gross wage in country $A$ falls. Per capita consumption in country $A$ still raises but less than the increase in $t_{A \alpha}$, 
because of the fall of $w_{A a}$. Per capita consumption in country $B$ raises as much as in country $A$, because mobility equalizes per capita consumption. Notice that how much $c_{A \alpha}$ increases following the increase in $t_{A \alpha}$ depends on $m$; for instance, in the symmetric case where $t_{A \alpha}=t_{B \alpha}, m=0$, and $\frac{d c_{A \alpha}}{d t_{A \alpha}}=\frac{d c_{B \alpha}}{d t_{B \alpha}}=1 / 2$.

Very much the same results would occur in period 2, as an effect of a change in $T_{A a}$ or $T_{B a}$ except that $k$ should be now substituted by $K \equiv$

$\left(\frac{N+m+M}{N-m-M}\right)^{\gamma-2}$ (see Appendix 1). But of course, as we discuss below, $T_{i a}$ is not set exogenously, but it is endogenously determined at the equilibrium in order to satisfy the intergovernmental governments' budget constraint.

\subsection{National fiscal policies}

Consider now fiscal policy, starting with the case where such a policy is run at the national level. Labor mobility introduces an additional constraint into the optimization problem faced by the fiscal authority, namely the fact that now net wages must be equated across the two countries (see equations 15 and 21), so their consumers must all share the same consumption path over time, even if their intertemporal preferences differ. This is the reason why labor mobility is not only useless in this context, but it is also potentially harmful, since countries might be forced to follow a suboptimal consumption smoothing plan.

As a preliminary step, we have to define the objective function of national governments. With labor mobility, the residents in a country might no longer coincide with its citizens. In principle, we could then think that a welfarist government could follow either a nationality principle or a residence principle (or a combination of the two). Under the first principle, a government maximizes the utility of its own citizens, regardless of the country in which they live. Under the second one, a government maximizes the utility of those people resident in the country, regardless of their nationality. Which hypothesis is more convincing depends on the institutional context. In the EMU area, for instance, living and working in an European country does not give a person the right to vote in that country; people still vote in their country of origin. Hence, if governments are welfarist because they want to get the votes of the people who are eligible to vote, the nationality principle would seem more reasonable for this context. Following this rule, the government of, say, country $A$, who has $m \geq 0$ people living in country $B$ in period 1 and 
$(m+M) \geq 0$ people living in country $B$ in period 2, would then maximize the following objective function (in state $\alpha$ ):

$$
\begin{aligned}
& (N-m) \ln \left(w_{A \alpha}+t_{A \alpha}\right)+m \ln \left(w_{B \alpha}+t_{B \alpha}\right)+ \\
& +(N-m-M) \delta_{A} \ln \left[W_{A \alpha}+T_{A \alpha}\right]+(m+M) \delta_{A} \ln \left[W_{B \alpha}+T_{B \alpha}\right]
\end{aligned}
$$

Notice however, by inserting the labor market equilibrium conditions (15) and (21), that under costless mobility, this objective function boils down to the following:

$$
N\left[\ln \left(w_{A \alpha}+t_{A \alpha}\right)+\delta_{A} \ln \left(W_{A \alpha}+T_{A \alpha}\right)\right]
$$

and the same reasoning applies to country $B^{9}$. Intuitively, each government should realize that because of costless mobility, in equilibrium the per capita consumption of each consumer in each period must be the same in both countries, so that the perfect labor mobility does not change the structure of each government preferences with respect to the case with no mobility.

Labor mobility does change the intertemporal budget constraints, however. In fact, assuming that a country cannot discriminate between national and not national residents in terms of labor taxation ${ }^{10}$ and cannot tax the labor income of not resident workers, these now become:

$$
\begin{aligned}
& (N-m) t_{A \alpha}(1+r)+(N-m-M) T_{A \alpha}=0 \\
& (N+m) t_{B \alpha}(1+r)+(N+m+M) T_{B \alpha}=0
\end{aligned}
$$

Notice that in the equations $m, T_{A \alpha}$, and $M$ are all functions of the tax/subsidies selected by both countries in the first period, as $T_{A \alpha}$ and therefore $M$, need to adjust in order to guarantee the budget constraint of each country in the second, and labor markets equilibrium conditions must also be respected in the both periods. This makes each budget constraint above a potentially very complex function of the first period tax rates.

\footnotetext{
${ }^{9} \mathrm{As}$ it is easy to check, the resident principle and the nationality principle would in general not coincide as the number of people resident in each period with costless mobility would be different, and as immigrants would carry their time preferences with them.

${ }^{10}$ This would seem implicit in any federation, however loose, that adopts a common currency. It is for example the case in the EMU, where discriminatory taxation is explicitly forbidden by the European treaties.
} 


\subsubsection{Nash equilibria}

The government in each country sets the optimal tax/subsidy rates by solving the following problem:

$$
\max _{t_{i \alpha}, T_{i \alpha}} \ln \left(w_{i \alpha}+t_{i \alpha}\right)+\delta_{i} \ln \left[W_{i \alpha}+T_{i \alpha}\right] \quad \text { for } i=A, B
$$

subject to its own budget constraint and to the mobility constraints defined in the previous section. In a Nash equilibrium, it also takes as given the fiscal choices of the other country. One potential difficulty in solving this problem is that it is not obvious that the problem is still convex after mobility has been taken into account. As it is well known by optimal taxation theory, this is not guaranteed by strict concavity of the objective function, once the optimal reactions of agents to taxation are taken into account. In our case, as we saw above, the problem is that the interplay between mobility and budget constraint makes the intertemporal budget constraint of government at points potentially not convex. In Appendix 2, we nevertheless show that the government optimizing problem is still well behaved at the equilibrium, provided that the elasticity of $m$ to tax differentials is not too high ${ }^{11}$. Assuming this to be the case, and solving governments problem, we obtain that at a Nash equilibrium the following first order conditions must be jointly satisfied $^{12}$ :

$$
\frac{C_{A \alpha}^{n}}{c_{A \alpha}^{n}}=-\delta_{A} \frac{d T_{A \alpha}}{d t_{A \alpha}} \frac{K}{k} \frac{1+k}{1+K} \text { and } \frac{C_{B \alpha}^{n}}{c_{B \alpha}^{n}}=-\delta_{B} \frac{d T_{B \alpha}}{d t_{B \alpha}} \frac{1+k}{1+K}
$$

where

$$
\begin{aligned}
& \frac{d T_{A \alpha}}{d t_{A \alpha}}=-(1+r) \frac{\left[(N-m)-t_{A \alpha} \frac{d m}{d t_{A \alpha}}\right]}{(N-m-M)-T_{A \alpha} \frac{d M}{d T_{A \alpha}}} \\
& \frac{d T_{B \alpha}}{d t_{B \alpha}}=-(1+r) \frac{\left[(N+m)-t_{B \alpha} \frac{d m}{d t_{A \alpha}}\right]}{(N+m+M)-T_{B \alpha} \frac{d M}{d T_{A \alpha}}}
\end{aligned}
$$

are derived by applying the implicit function theorem to the budget constraints (26) and (27) respectively.

\footnotetext{
${ }^{11}$ For $\gamma \rightarrow 0$, or $\gamma \rightarrow 1$, the problem has no solution as $m$ will became infinitely elastic to the tax rate differentials.

${ }^{12}$ To increase the readibility of the formulas we express these conditions as function of $T_{i s}$, without solving explicitly for the latter. See Appendix 2 for an alternative formulation.
} 
By continuity of the reaction functions, it is easy to show that a Nash equilibrium generally exists. A different matter is to establish whether this equilibrium is also unique. In Appendix 2 we provide conditions for this to be the case, although the complexity of the formulas does not allow for an easy interpretation of these conditions. Fortunately, our point here does not rely on the uniqueness of the Nash equilibrium and our statements below can be thought as referring to any possible Nash equilibria.

Comparing the FOC above with the corresponding conditions in absence of labor mobility, it is clear that labor mobility in general distorts the optimal consumption path chosen by the two governments. Hence, we would not expect the Nash equilibria to be in general Pareto efficient. Still, in the special case where $\delta_{A}=\delta_{B}=\delta$, we can prove the following result.

Proposition 2 If $\delta_{A}=\delta_{B}=\delta, t_{i s}^{n}=t_{s}^{*}($ for $s=\alpha, \beta$ and $i=A, B)$ is a Nash equilibrium.

where the suffix " $n$ " indicates that we are considering the optimal tax rates at the Nash equilibrium. Notice that if $t_{i s}^{n}=t_{s}^{*}, m=M=0$, and $\frac{d T_{A \alpha}}{d t_{A \alpha}}=\frac{d T_{B \alpha}}{d t_{B \alpha}}=-(1+r)$; substituting in the FOC above we get $\frac{C_{i \alpha}^{n}}{c_{i \alpha}^{n}}=$ $\frac{C_{i \alpha}^{*}}{c_{i \alpha}^{*}}=\delta(1+r)$ for $i=A, B$, which is the optimal Euler condition for the case without mobility. Hence, if the time preferences are the same across countries, perfect labor mobility is without consequences; at the symmetric Nash equilibrium, the same Pareto efficiency allocations would result, exactly because no consumer would move at the equilibrium ${ }^{13}$.

The intuition for this result is quite simple. Suppose that starting from the allocation $t_{i s}^{n}=t_{s}^{*}$ country $A$ considers raising the subsidy (or reducing the tax) by 1 euro in the first period. As we show in Proposition 1, (at $m=0$ ) this would increase the consumption of his citizens by $1 / 2$ euro in the first period, because, as a consequence of labor mobility, the subsidy would be perfectly shared with the consumers of country $B$. Normally, this should lead country $A$ to set the subsidy at an inefficient lower level, as country $A$ does not care for the benefits accruing to consumers of country $B$. However, in the second period, because of perfect labor mobility, the additional cost of the increased subsidy would also be shared by the consumers in country $B$,

\footnotetext{
${ }^{13}$ There could be other Nash equilibria of course, but with identical countries a symmetric Nash equlibrium would seem to be a focal point where countries' expectations would converge.
} 
imposing only a cost equal to $(1+r) / 2$ euro to the consumers living in $A$. But this is exactly the optimal trade off between consumption in the two periods for country $A$ at $t_{i s}^{n}=t_{s}^{*}$, which means that at $t_{s}^{*}$ country $A$ is indifferent between raising (or reducing) the transfer by 1 euro or stick at $t_{s}^{*}$. Hence, $t_{s}^{*}$ is a Nash equilibrium. The argument also provides an intuition on why the Nash equilibrium is in this case Pareto efficient; it is as if perfect labor mobility leads the two countries to perfectly endogeneize the consequences of their actions, so eliminating one of the potential source of inefficiency of the Nash equilibria ${ }^{14}$.

There is also a second, simpler, argument that can be used to prove the same result (and it is indeed used in the proof of the Proposition in Appendix 1). Suppose on the contrary that $t_{s}^{*}$ is not a Nash equilibrium; than, one of the two countries, say country $A$, must have a feasible deviation from this equilibrium that is beneficial for country $A$. But because of labor mobility and common preferences across countries, if this deviation is beneficial for country $A$ it must also be beneficial for country $B$. But then the deviation by $A$ would represent a Pareto improvement with respect to the consumption allocation defined by $t_{s}^{*}$, contradicting the fact that this allocation is Pareto efficient.

Notice that this same argument can be used to show that Nash equilibria when $\delta_{A} \neq \delta_{B}$ cannot be Pareto efficient; perfect labor mobility would still lead the two countries to internalize the consequences of their actions, but as second time consumption is now evaluated differently by the different countries, unilateral beneficial deviation for a country is now possible at the original allocations. In particular, it is easy to show that with different time preferences the first best tax rates defined by $t_{s}^{*}$ cannot longer be sustained as a Nash equilibrium under perfect mobility. These allocations would entail different tax rates in the first period, and therefore induce labor mobility that

\footnotetext{
${ }^{14}$ Indeed, one may wonder if there exist other Nash equilibria with identical countries still charaterized by the same efficient level of consumption in the two periods, but different tax rates. Say, country $A$ setting a subsidy in the first period that would enforce however the Pareto efficient consumption vector $c_{i s}^{*}, C_{i s}^{*}$ in the two countries and country $B$ replying with $t_{B \alpha}=0$. The answer is no. This is so because with different tax rates $m$ would be different from zero, which would also imply that the slope of the budget constraint would not be equal to $1+r$. Thus, even if country $A$ managed to choose $t_{A \alpha}$ so as to get $c_{i s}^{*}$ in the first period with $m \neq 0$ (see Proposition 1), it could not afford $C_{i s}^{*}$ in the second period, because this allocation would violate its budget constraint. This argument also proves that if asymmetric Nash equilibria exist with identical countries, they must be Pareto inefficient.
} 
would violate the intergovernmental budget constraint of the governments. Formally,

Proposition 3 If $\delta_{A} \neq \delta_{B}$, at the Nash equilibrium it is either $t_{A s}^{n} \neq t_{B s}^{n}$ or $T_{A s}^{n} \neq T_{B s}^{n}$ or both (for $s=\alpha, \beta$ ), and it is $m \neq 0$ and $M \neq 0$. The equilibrium is not Pareto efficient.

At a Nash equilibrium, with different time preferences the two national governments will set different tax/subsidy rates. For example, if country $A$ is more "impatient" than country $B\left(\delta_{A} \leq \delta_{B}\right)$ it will be $t_{A}^{n} \geq t_{B}^{n}$ when the shock in the first period is negative. However, people will move and gross wages adjust, so that the time path of consumption will be the same across the two countries. As a consequence, the two countries are forced to follow a consumption path different from the Pareto efficient path obtained in the absence of labor mobility. Formally:

$$
\frac{C_{A \alpha}^{n}}{c_{A \alpha}^{n}}=\frac{C_{B \alpha}^{n}}{c_{B \alpha}^{n}}, \frac{C_{A \alpha}^{n}}{c_{A \alpha}^{n}} \neq \frac{C_{A \alpha}^{*}}{c_{A \alpha}^{*}}, \frac{C_{B \alpha}^{n}}{c_{B \alpha}^{n}} \neq \frac{C_{B \alpha}^{*}}{c_{B \alpha}^{*}}
$$

\subsection{Federal fiscal policy}

Let us now then turn to federal fiscal policy. Recall that a federal government is defined here as a fiscal authority which sets the tax/subsidy rates in both countries, after observing the state of nature (in period 1). Moreover, we distinguish between a weak federation (coordination), where each government's intertemporal budget constraint must clear, and a strong federation (federal budget), where the aggregate intertemporal budget constraint must clear. Consider first the latter case.

The federal government maximizes the following social welfare function:

$\max _{t_{A \alpha}, t_{B \alpha}, T_{A \alpha}, T_{B \alpha}} \ln \left(w_{A \alpha}+t_{A \alpha}\right)+\delta_{A} \ln \left[W_{A \alpha}+T_{A \alpha}\right]+\ln \left(w_{B \alpha}+t_{B \alpha}\right)+\delta_{B} \ln \left[W_{B \alpha}+T_{B \alpha}\right]$

subject to the following aggregate budget constraint:

$(N-m) t_{A \alpha}(1+r)+(N+m) t_{B \alpha}(1+r)+(N-m-M) T_{A \alpha}+(N+m+M) T_{B \alpha}=0$ 
where again gross wages and mobility in both periods are determined by the equilibrium conditions in the labor market (see equations 16-18 and 22 24).

Again, we assume that even after inserting the reaction function of the individuals in the objective functions, the problem is still globally convex so that it entails a unique solution (see again the discussion in the Appendix $2)$.

The FOCs for this problem can be written as follows:

$$
\begin{gathered}
\frac{C_{A \alpha}^{f}}{c_{A \alpha}^{f}}=\bar{\delta} \frac{(N-m)(1+r)+\frac{d m}{d t_{A}}\left[(1+r)\left(t_{B \alpha}-t_{A \alpha}\right)+T_{B \alpha}-T_{A \alpha}\right]}{(N-m-M)+\frac{d M}{d T_{A \alpha}}\left(T_{B \alpha}-T_{A \alpha}\right)} \frac{K}{k} \frac{1+k}{1+K} \\
\frac{C_{B \alpha}^{f}}{c_{B \alpha}^{f}}=\bar{\delta} \frac{(N+m)(1+r)+\frac{d m}{d t_{A}}\left[(1+r)\left(t_{A \alpha}-t_{B \alpha}\right)+T_{A \alpha}-T_{B \alpha}\right]}{(N+m+M)+\frac{d M}{d T_{A \alpha}}\left(T_{A \alpha}-T_{B \alpha}\right)} \frac{1+k}{1+K}
\end{gathered}
$$

where $\bar{\delta} \equiv \frac{\delta_{A}+\delta_{B}}{2}$ is the average discount factor.

By perfect labor mobility, per capita consumption levels in each country in each period must be equalized; that is, that the LHS of the equations above must be the same. This implies that the RHS of the two equations must also be the same. Inspecting the formulas at the RHS of both equations, it is clear that there is only one solution to the above problem that satisfies both equations simultaneously. This is for the federal government to set the same tax/subsidy rate in both countries in each period, that also implies that no one moves at the equilibrium.

Proposition 4 The federal government sets $t_{i s}^{f}=t_{s}^{f}$ and $T_{i s}^{f}=T_{s}^{f}$, for $s=$ $\alpha, \beta$ and $i=A, B$. The equilibrium number of people moving is $m=M=0$. In both countries the consumption path is:

$$
\frac{C_{i s}^{f}}{c_{i s}^{f}}=\bar{\delta}(1+r) \quad \text { for } s=\alpha, \beta \text { and } i=A, B .
$$

Intuitively, as mobility is useless, the federal government simply eliminates it by setting the same tax rates everywhere in each period, and it takes into account the different time preferences of the two countries by setting 
the time path of consumption according to the average time preference. Notice that because of the aggregate budget constraint, the federal government could in principle enforce compensating lump sum transfers across countries and let countries set different tax rates. But this would be costly, and because of mobility the desires of at least one country would be frustrated at the equilibrium, since the consumption path would still have to be the same for both countries. Hence, the optimal solution is to eliminate mobility altogether and to find a compromise between the two different time preferences.

In the special case where $\delta_{A}=\delta_{B}=\delta=\bar{\delta}, t_{i s}^{f}=t_{i s}^{n}=t_{s}^{*}$ (for $s=$ $\alpha, \beta$ and $i=A, B)$, the federal choice coincides with the national solutions and is also Pareto efficient. When preferences differ, the federal government is also constrained by mobility and cannot replicate the optimal solutions $t_{i s}^{*}$. But because the federal solution takes into account the utility function of both countries, we can safely conclude that in the presence of different time preferences the federal solution represents however at least a potential Pareto improvement with respect to any Nash equilibrium, meaning that the winner at the federal solution could in principle compensate the loser and still being better off ${ }^{15}$. Finally, notice that the allocation achieved by the federal government under the assumption of a strong federation, could be implemented also by the weak form of federation. This is so because mobility at the federal solution is zero, and therefore by construction not only the aggregate budget constraint, but also the budget constraint of each country must be satisfied at the federal solution. We then conclude that in the presence of symmetric shocks, coordination is enough to reach Pareto improving solutions and there is no need of a federal budget.

Still, notice that even the federal solution falls short of the first best solutions that would be reached with no mobility. At the federal solution with perfect tax mobility, countries need to compromise on a unique tax rate, while each country would be better off by choosing a different tax rate in line with their time preferences. Hence, when shocks are symmetric and preferences differ, the optimal policy is still to forbid mobility altogether.

\footnotetext{
${ }^{15}$ It cannot be an actual Pareto improvement, if compensating transfers are no paid, as at least one country would be made worse off at the federal solution with respect to the Nash equilibrium. This is so because both the federal solution and the Nash equilibria lie in between the optimal choices of the countries in absence of mobility. Hence, the country whose preferred allocation is closer to the Nash equilibrium would necessarily be worse off at the federal solution.
} 


\section{Asymmetric shocks}

Let us then consider the case where shocks are asymmetric. In this case, the possibility to move across countries for workers plays a positive efficiency role. Suppose for example that country $A$ is hit by a negative productivity shock and country $B$ by a positive one. These shocks introduce a positive wedge between the wages in $B$ and $A$, since they increase and decrease the labour productivity in the two countries, respectively. As a consequence people will move from $A$ to $B$ until the wage wedge vanishes, and in doing so they make the average productivity of labour across the two countries go up. Therefore there is an efficiency gain from labor mobility. Full mobility also plays an insurance role; by moving in the lucky countries, workers of the countries hit by the negative shock can insure themselves against the occurrence of negative shock in their country. Still, a remarkable result of the analysis below is that the federal fiscal policy enables all consumers to enjoy the full efficiency gain they can get from labor mobility, while this is not true with national fiscal policies.

\subsection{Assumptions and game structure}

All the assumptions of the model and the structure of the game remain unchanged, except for the following:

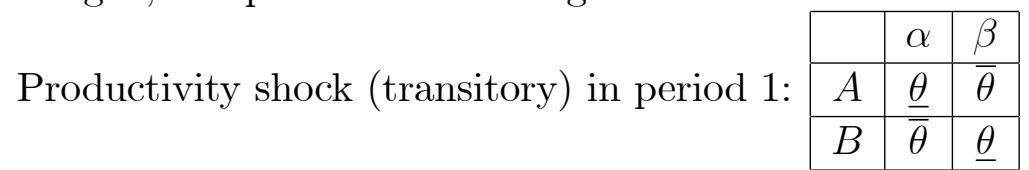

The two countries are now hit by opposite productivity shocks in period 1 , that again disappear in period 2.

\subsection{The labour market with labour mobility}

Let us see first how labor market equilibrium conditions change with asymmetric shocks. We focus on state $s=\alpha$; the analysis for $s=\beta$ is the same, with the productivity shock reversed in the two countries.

Period 2. The analysis of the previous section still applies, since in the second period the productivity shocks vanish, so the two countries share the same productivity parameter $\Theta$. Therefore the equilibrium conditions of the labor market are unaffected by the asymmetry of the productivity shocks, which hit the two countries only in period one. 
Period 1. The equilibrium conditions in the labor market are affected in the first period. In particular, equation (20) becomes:

$$
\left(\frac{\bar{\theta} \gamma}{w_{B \alpha}}\right)^{\frac{1}{1-\gamma}}=N+m
$$

since country $B$ is hit by a positive productivity shock. As a consequence, the equilibrium wage in this country is now:

$$
w_{B \alpha}=\bar{\theta} \gamma(N+m)^{\gamma-1}
$$

and the equilibrium condition (24) is modified as follows:

$$
\gamma\left[\underline{\theta}(N-m)^{\gamma-1}-\bar{\theta}(N+m)^{\gamma-1}\right]+t_{A \alpha}-t_{B \alpha}=0
$$

from which the equilibrium number of people moving in the first period $m$ is implicitly defined. Notice that now $m$ does not only depend on the difference between $t_{A \alpha}$ and $t_{B \alpha} ; m>0$ even if this difference were zero, as $\bar{\theta}>\underline{\theta}$. Still, we can compute:

$$
\frac{d m}{d t_{A \alpha}}=\frac{1}{\gamma(\gamma-1)\left[\underline{\theta}(N-m)^{\gamma-2}+\bar{\theta}(N+m)^{\gamma-2}\right]}<0 \text { and } \frac{d m}{t_{B \alpha}}=-\frac{d m}{t_{A \alpha}}
$$

Easy computations show that the derivatives of the equilibrium wages relative to the tax/subsidy rates are still written as in equations (48), with the only difference that $k$ is now defined by:

$$
k \equiv \frac{\bar{\theta}}{\underline{\theta}}\left(\frac{N+m}{N-m}\right)^{\gamma-2}
$$

By modifying $k$ accordingly, Proposition 1 still holds.

\subsection{Federal fiscal policy}

In the case of asymmetric shocks, it is more useful to start the analysis by considering the federal solution. Consider the strong federation first. The federal government's problem is still defined by the objective function (32) together with the aggregate budget constraint (33). Solving the problem, the 
FOCs are still given by equations (34) and (35), taking into account that the derivative $\frac{d m}{d t_{A \alpha}}$ is now given by (40) and $k$ by $(41)^{16}$.

The next proposition shows that the federal fiscal policy that we examined in the previous section still solves the federal government's problem, even with asymmetric shocks. The federal government sets the same tax/subsidy rate in both countries and both countries follow the same consumption path, determined by the average discount factor.

Proposition 5 Under asymmetric shocks, the federal government sets $t_{i s}^{f}=$ $t_{s}^{f}$ and $T_{i s}^{f}=T_{s}^{f}$, for $s=\alpha, \beta$ and $i=A, B$. The equilibrium gross wage in period 1 is $w^{f}>\frac{1}{2}(\bar{w}+\underline{w})$ in both countries. The equilibrium number of people moving is $m^{f} \neq 0$ and $M^{f}=-m^{f}$ in periods 1 and 2 respectively. In both countries the consumption path satisfies the Euler equation:

$$
\frac{C_{s}^{f}}{c_{s}^{f}}=\bar{\delta}(1+r) \quad \text { for } s=\alpha, \beta
$$

Intuitively, labor mobility is now useful, and the federal government has no reason to interfere with it. But efficiency enhancing mobility can be obtained by simply setting the same tax rate everywhere, because in this case workers will only move following the realization of the shock and therefore increasing aggregate production and average wage. Further mobility induced by different tax rates generates only welfare costs and no aggregate benefits, as consumption vectors would still be equalized across countries. This also implies that when the two countries differ in their time preferences $\left(\delta_{A} \neq\right.$ $\left.\delta_{B}\right)$, labor mobility introduces a trade-off. On one hand, both countries are forced to follow the same consumption path: under this regard, the federal policy maximizes the social welfare by implementing a consumption vector proportional to the average discount factor. On the other hand, labor mobility allows both countries to enjoy an efficiency gain: again, the federal fiscal policy plays a positive role, since in equilibrium people move to fully exploit the productivity shock. This process enables all workers to get a gross wage larger than the average wage they would get without any labour mobility. Notice that both $w^{f}$ and $m^{f}$ are increasing in the size of the productivity shock $\varepsilon$, so that efficiency enhancing role of mobility the larger is the larger is the productivity shock.

\footnotetext{
${ }^{16}$ The formulas for $d M / d T$ and $K$ remain unchanged as in the second period the shock disappears.
} 
When the two countries share the same time preferences $\left(\delta_{A}=\delta_{B}\right)$, the constraint to follow the same consumption path over time is not binding, so the negative side of this trade-off vanishes. Therefore the federal fiscal policy is able to achieve a first best allocation in presence of labor mobility: the welfare of all consumers is higher than in absence of labor mobility, thanks to the gain in productivity.

Finally, notice that the allocation achieved under a strong federation cannot be replicated by a weak federation, because mobility would induce a violation in at least one of the budget constraints of the two countries. Intuitively, if $t_{s}^{f}>0$, country $B$, that receives $m$ immigrants in the first period, would not to able to finance the debt in the second period with $T_{s}^{f}$, when the immigrants go back home. In other words, the federal budget is necessary to achieve the allocation stated in Proposition 5. The federal government can impose the same (federal) tax/subsidy to workers whenever they decide to live; hence, it is not constrained by the national budget constraint and can implicitly introduce transfers across countries. Thus, in presence of asymmetric shocks the strong federation Pareto dominates the weak federation.

\subsection{National fiscal policies}

Consider then the case where the fiscal policy is run at the national level. We can show that the two national fiscal policies lead to equilibria ${ }^{17}$ which are necessarily different from that obtained by the federal government, and they lead to a lower social welfare. Quite interestingly, this happens for any values of intertemporal preferences, in particular even for $\delta_{A}=\delta_{B}$. At the equilibrium with national fiscal policies, the number of people moving is necessarily different from that enabling the two countries to equate their marginal labour productivity $\left(\mathrm{m}^{f}\right)$, which is instead obtained with a federal fiscal policy; therefore a federal government is able to achieve a strict Pareto improvement over the national governments.

The national governments' problem is still defined by the objective function (25) together with the budget constraints (26) and (27). The FOCs are still given by equations (29), taking into account that - in equations (30) and (31) - the derivative $\frac{d m}{d t_{A \alpha}}$ is now given by (40) and $k$ by (41).

\footnotetext{
${ }^{17}$ The discussion on the uniqueness of the Nash equilibrium in Appendix 2 extends to the case of asymmetric shocks, by changing $k$ and the formula for $m$ (see the remark concluding Appendix 2).
} 
Proposition 6 With asymmetric productivity shocks, in a Nash equilibrium it is either $t_{A s}^{n} \neq t_{B s}^{n}$ or $T_{A s}^{n} \neq T_{B s}^{n}$ or both (for $s=\alpha, \beta$ ), and it is $m \neq m^{f}$. The equilibrium is not Pareto efficient.

The reason why the two national governments cannot follow the same fiscal policy in both periods relies on their own budget constraints under mobility. To get the intuition behind this result, focus on the state $s=\alpha$. Suppose the two governments set the same subsidy rate $t>0$ in the first period. Then people move in order to equate their wages across the two countries. In particular, people will move from $A$ to $B$; then the subsidy will be given to a lower number of people in country $A$ than in $B$. If the tax rate $T<0$ were the same in the two countries, they would end up with the same number of people $N$ in the second period (since wages are equated only if the supply of labour is the same across countries). But then the tax rate in period two should be lower in country $A$, since in the previous period a lower number of people have received the subsidy: this contradicts the starting point that the tax rates are the same across countries in both periods. Hence, even if countries have the same time preferences, any Nash equilibrium must be characterized by different tax rates across them. But with different tax rate, mobility in the first period must be necessarily different from the one that maximizes production and wages. Hence, total production is below the optimal one that could be reached under a federal government with the ability to impose federal taxes. Hence, a strong federation introduce a Pareto improvement with respect to national policies.

A weak federation could still improve on Nash equilibria, because it would solve a coordination problem. But it could not reach the optimum, because it would still be unduly constrained by the national budget constraints. Our conclusion therefore is that exactly when mobility is potentially useful, because it could introduce efficiency gains, that a strong federation and a federal budget is needed.

\section{$5 \quad$ Extensions}

The above model relies on many simplifying assumptions, and it could obviuolsy be extended in several directions. For example, we might relax the assumption that consumers have no access to capital markets, introducing private saving, and model in a more sophisticated way the imperfections of 
capital markets. Or we might explicitely take into account the returns to the fix factor of production. We might also consider more complex objective functions of the Government, including tasks different from the only consumption smoothing objective considered here, for example the provision of a public good. But it seems highly unlikely that the qualitative conclusions of the previous model could be modified by these extensions, as the basic feature of the model, that regional governments are constrained in their fiscal choices by labor mobility, would remain unchanged. And as long as fiscal policy is beneficial for consumers and governments are welfare maximizers, the federal solution must necessarily dominate the Nash equilibrium of independent national policies. One might instead wonder if the results above require the assumption of costless labor mobility, which is obviously unrealistic. The answer is no ${ }^{18}$.

\subsection{Costly mobility}

Suppose then that inside the federation, labor mobility is possible, but costly for the people involved, with mobility costs distributed in the workers' population according to some distribution function (say, uniform for simplicity). All other assumptions, concerning production functions and preferences remain unchanged. Consider first the simpler case with symmetric shocks, that is, a situation where labor mobility is useless in efficiency terms and can only be generated by difference in the fiscal behavior of the two countries.

Let us start our discussion by analysing the outcome of national fiscal policies. The first interesting observation is that there is now an externality effect at work. If say country A reduces his subsidy/tax rate in the first period and, as a consequence, $\mathrm{A}$ loses people to $\mathrm{B}$ in this period, those A people living in B would not get the same utility as the $\mathrm{B}$ original residents, because they would incur in some mobility costs. Even under the national principle, this distortion would then lead the A country government to count less the increase in B utility than it would do under full mobility, leading to inefficient choices. Hence, one can prove, that differently to the case with perfect mobility, even with identical time preferences, costly labor mobility induces a distortion in the optimal tax/transfer rates of the two countries, leading to suboptimal insurance under the negative shock and to over insurance for the

\footnotetext{
${ }^{18}$ The following discussion relies on results formally stated in a previuos version of this paper, available from the authors. We limit here to an informal discussion to save space.
} 
positive one.

The second observation is that, analogously to the full mobility case, when the discount rates differ across the two countries, the two governments will set two different tax/subsidy rates between them. However, labor mobility - despite the fact that it is costly - will constraint the two countries to have tax rates closer than they would choose with no labor mobility. As a consequence, the equilibrium will be again Pareto inefficient, unless of course mobility costs are so large that no one moves at the equilibrium.

Let us now turn to the federal fiscal policy. Again, we distinguish between two possible forms of federal intervention, a weak (coordination) and a strong federation (federal budget). As we have just argued, costly mobility induces an externality effect across countries, an issue that is not present under perfect mobility. Thus, it is quite intuitive that federal coordination Pareto dominates the national fiscal choices even with identical preferences, since the federal govenment internalizes those externalities that national governments fail to take into account. In particular, it can be shown that coordination with identical preferences is enough to reach the first best solution in the symmetric case: the federal government would select the same tax rate in both countries fully internalizing the externality effect, and both countries would be strictly better off under coordination than they are under national fiscal policy.

When preferences differ across countries, the federal government will not choose to equalize the tax rates across the two countries, differently from the full mobility case. The reason is that costly mobility allows consumption to differ across countries and across periods, and the federal government exploits this advantage, trading it off with the costs that a choice of different first period transfer induce in terms of positive and costly mobility. At the federal equilibrium with coordination only, the different tax rates chosen by the federal government will be generally closer than at the Nash equilibrium between the different countries.

Finally, a strong federation will lead to a better allocation than a weak federation, since the federal government can use the extra room provided by the federal budget to ease the distortions in the optimal consumption plans of the two countries. In particular, the federal government will now try to exploit more fully the advantage of costly mobility by selecting tax rates that are closer to the time preferences of the two countries, introducing implicit transfers across countries.

These results extend naturally to the case of asymmetric shocks, that is, 
efficiency enhancing labor mobility. Here, the federal government would try to exploit more fully the advantage of mobility by selecting closer tax rates than at the Nash equilibrium and internalizing the externality effects. And again, a strong federation would Pareto dominate a weak one, by allowing for intergovernmental transfers across countries.

\section{Concluding remarks}

In this paper we re-examine the well known proposition that an optimal currency area requires perfect labor mobility in order to work smoothly. Since first formulated by Robert Mundell, this proposition has become part of the common wisdom on optimal currency areas, and has been used, for instance, to criticize the current functioning of the EMU. We enrich the usual framework by considering an intertemporal setting and the possibility of efficiency enhancing fiscal policy, due to imperfections in the working of capital markets. We get quite different results from the conventional view. Even when labor mobility is perfect and it is potentially efficiency enhancing because the member countries of the currency union are hit by temporary asymmetric shocks, national fiscal policies alone are not able to reach the first best equilibrium. The reason is that at the equilibrium countries are induced to compete in order to attract the mobile workers and their tax bases and this leads to inefficient level of mobility. We also show that a federal government with the ability of imposing federal labor taxes could solve the problem, generating a strict Pareto improvement and allowing only for that regional mobility that maximizes aggregate production and welfare. The reason is that the federation has the advantage of being able to tax individuals wherever they decide to live and therefore to implicitly introduce transfers across countries, a possibility that is not open to national countries or regions. Hence, contrary to the conventional vision, a federal budget appears to be essential to the efficient working of a currency area, in particular when labor mobility is efficiency enhancing. Labor mobility and federal budget are not substitute but complement each other in a optimal currency union.

The model we discussed here is of course a far cry from realism. But certainly our conclusions do not support the view that lack of labor mobility is the main problem of the EMU. Even in our narrow perspective, lack of a federal government and of a federal budget would seem to be at least as problematic. 
Finally, we have discussed in some detail the implications of costly mobility, showing that our basic conclusions remain unchanged. Of course, other extensions of the model could be considered. Governments are not always welfare maximizers, public expenditure and debt are not only used to smooth consumptions across periods, private citizens and not only governments can to some extent gain access to capital markets, governments do bankrupt sometimes and markets are not perfectly competitive. But while discussing all these possible extensions could be interesting, we believe that our basic point is sound and would survive all these extensions. Labor mobility (and more generally factor mobility) may interfere with national (or regional) dynamic fiscal policy, because by moving people (and factors) might reduce future tax bases. This may make unsustainable a dynamic fiscal path that would otherwise be beneficial for citizens. A federation with tax powers and the possibility of introducing transfers across countries or regions can ease this problem.

\section{APPENDIX 1: Proofs}

\section{Proof of Proposition 1}

Period 2. By applying the implicit function theorem to equation (18), we get:

$$
\begin{aligned}
\frac{d M}{d T_{A \alpha}} & =\frac{1}{\Theta \gamma(\gamma-1)\left[(N-m-M)^{\gamma-2}+(N+m+M)^{\gamma-2}\right]}<0 \\
\text { and } \frac{d M}{T_{B \alpha}} & =-\frac{d M}{T_{A \alpha}}>0
\end{aligned}
$$

From equations (16) and (17) we can derive:

$\frac{d W_{A \alpha}}{d T_{A \alpha}}=\frac{d W_{A \alpha}}{d M} \frac{d M}{d T_{A \alpha}}=-\frac{1}{1+K}<0$ and $\frac{d W_{B \alpha}}{d T_{B \alpha}}=\frac{d W_{B \alpha}}{d M} \frac{d M}{d T_{B \alpha}}=-\frac{K}{1+K}<0$

where

$$
K \equiv\left(\frac{N+m+M}{N-m-M}\right)^{\gamma-2}>0
$$


Period 1. By applying the implicit function theorem to equation (24), we get:

$$
\frac{d m}{d t_{A \alpha}}=\frac{1}{\underline{\theta} \gamma(\gamma-1)\left[(N-m)^{\gamma-2}+(N+m)^{\gamma-2}\right]}<0 \text { and } \frac{d m}{t_{B \alpha}}=-\frac{d m}{t_{A \alpha}}>0
$$

From equations (22) and (23) we can derive:

$$
\frac{d w_{A \alpha}}{d t_{A \alpha}}=\frac{d w_{A \alpha}}{d m} \frac{d m}{d t_{A \alpha}}=-\frac{1}{1+k}<0 \text { and } \frac{d w_{B \alpha}}{d t_{B \alpha}}=\frac{d w_{B \alpha}}{d m} \frac{d m}{d t_{B \alpha}}=-\frac{k}{1+k}<0
$$

where

$$
k \equiv\left(\frac{N+m}{N-m}\right)^{\gamma-2}>0
$$

\section{Proof of Proposition 2.}

Let be $\delta \equiv \delta_{A}=\delta_{B}$.

Consider the state $s=\alpha$. Let be $m=M=0$. From equations (16) and (17) we get: $W_{i \alpha}=W^{*}$ for $i=A, B$. From equations (22) and (23) we get $w_{i \alpha}=\underline{w}$ for $i=A, B$. The budget constraints (26) and (27) boil down to $t_{i \alpha}(1+r)+T_{i \alpha}=0$ for $i=A, B$; hence $\frac{d T_{i \alpha}}{d t_{i \alpha}}=-(1+r)$ for $i=A, B$. It is also $K=k=1$. Therefore the two FOCs (29) boil down to the standard Euler equation (10) with $\delta_{i}=\delta$ for $i=A, B$, from which the equilibrium tax/subsidy rates are $t_{i \alpha}=t_{\alpha}^{*}, T_{i \alpha}=-t_{\alpha}^{*}(1+r)$ for $i=A, B$.

To show that this is a Nash equilibrium, consider a deviation by one country, say $A$, from $t_{\alpha}^{*}$ to $t_{\alpha}^{*}+d t_{A \alpha}$ and suppose that this deviation increases the intertemporal utility of consumers of country A. However, as for $\delta_{i}=\delta$ the two countries have the same preferences, and by perfect labor mobility consumption is equalized in each country in each period, this means that consumers of country B would also gain from the change. But this would mean that the change from $t_{\alpha}^{*}$ to $t_{\alpha}^{*}+d t_{A \alpha}$ is a Pareto improving move, which would contradict the fact that $t_{i \alpha}=t_{\alpha}^{*}$ is Pareto efficient. This means that there cannot exist a unilateral deviation from $t_{\alpha}^{*}$ that benefits a single country. Hence, $t_{i \alpha}=t_{\alpha}^{*}$ is a Nash equilibrium. The same reasoning applies to the state $s=\beta$. QED

\section{Proof of Proposition 3}


Let be $\delta_{A}<\delta_{B}$. Consider the state $s=\alpha$. Let $m=M=0$. From equations (16) and (17) we get: $W_{i \alpha}=W^{*}$ for $i=A, B$. From equations (22) and (23) we get $w_{i \alpha}=\underline{w}$ for $i=A, B$. From equations (18) and (24), it follows that $t_{A \alpha}=t_{B \alpha}$ and $T_{A \alpha}=T_{B \alpha}$. Hence $C_{A \alpha}=C_{B \alpha}$ and $c_{A \alpha}=c_{B \alpha}$, and $\frac{C_{A \alpha}}{c_{A \alpha}}=\frac{C_{B \alpha}}{c_{B \alpha}}$. But $m=M=0, t_{A \alpha}=t_{B \alpha}$ and $T_{A \alpha}=T_{B \alpha}$ also imply that $\frac{d T_{A \alpha}}{d t_{A \alpha}}=\frac{d T_{B \alpha}}{d t_{B \alpha}}$ (see equations $30-31$ ), and from the FOCs (29) we get: $\frac{C_{A \alpha}^{n}}{c_{A \alpha}^{n}}<\frac{C_{B \alpha}^{n}}{c_{B \alpha}^{n}}\left(\right.$ since $\left.\delta_{A}<\delta_{B}\right)$. Therefore at least one country has an incentive to deviate. So in equilibrium it cannot be $m=M=0$.

Now let $t_{A \alpha}=t_{B \alpha}$ and $T_{A \alpha}=T_{B \alpha}$. From equations (18) and (24), it follows that $m=M=0$, but this cannot be the case in equilibrium, as we have seen above. So in equilibrium it cannot be $t_{A \alpha}=t_{B \alpha}$ and $T_{A \alpha}=T_{B \alpha}$.

Finally, the equilibrium conditions in the labor market (equations 15 and 21) imply that it must be $\frac{C_{A \alpha}^{n}}{c_{A \alpha}^{n}}=\frac{C_{B \alpha}^{n}}{c_{B \alpha}^{n}}$. But the Euler equation (10) imply that $\frac{C_{A \alpha}^{*}}{c_{A \alpha}^{*}}<\frac{C_{B \alpha}^{*}}{c_{B \alpha}^{*}}\left(\right.$ with $\left.\delta_{A}<\delta_{B}\right)$. Therefore it cannot be $\frac{C_{A \alpha}^{n}}{c_{A \alpha}^{n}}=\frac{C_{A \alpha}^{*}}{c_{A \alpha}^{*}}$ and $\frac{C_{B \alpha}^{n}}{c_{B \alpha}^{n}}=\frac{C_{B \alpha}^{*}}{c_{B \alpha}^{*}}$.

The same reasoning applies to the state $s=\beta$. QED

\section{Proof of Proposition 4}

Consider the state $s=\alpha$. The cross-country equality of net wages (see equations (15 and 21)) implies $\frac{C_{A \alpha}^{f}}{c_{A \alpha}^{f}}=\frac{C_{B \alpha}^{f}}{c_{B \alpha}^{f}}$, which in turn implies (by equating the RHS of the FOCs 34 - 35) the following condition:

$$
\begin{gathered}
\frac{(N-m)(1+r)+\frac{d m}{d t_{A}}\left[(1+r)\left(t_{B \alpha}-t_{A \alpha}\right)+T_{B \alpha}-T_{A \alpha}\right]}{(N-m-M)+\frac{d M}{d T_{A \alpha}}\left(T_{B \alpha}-T_{A \alpha}\right)} \frac{K}{k}= \\
=\frac{(N+m)(1+r)+\frac{d m}{d t_{A}}\left[(1+r)\left(t_{A \alpha}-t_{B \alpha}\right)+T_{A \alpha}-T_{B \alpha}\right]}{(N+m+M)+\frac{d M}{d T_{A \alpha}}\left(T_{A \alpha}-T_{B \alpha}\right)}
\end{gathered}
$$

and a solution to this equation is: $t_{i \alpha}=t_{\alpha}, T_{i \alpha}=T_{\alpha}$ for $i=A, B$ and $m=M=0$. Hence both the FOCs boil down to the Euler equation (36). The equilibrium conditions in the labor market give: $W_{i \alpha}=W^{*}$ and $w_{i \alpha}=\underline{w}$, for $i=A, B$.

The same reasoning applies to the state $s=\beta$.

\section{Proof of Proposition 5}


Consider the state $s=\alpha$. The cross-country equality of net wages (see equations (15 and 21)) implies $\frac{C_{A \alpha}^{f}}{c_{A \alpha}^{f}}=\frac{C_{B \alpha}^{f}}{c_{B \alpha}^{f}}$, which in turn implies (by equating the RHS of the FOCs 34 - 35) the following condition:

$$
\begin{aligned}
& \frac{(N-m)(1+r)+\frac{d m}{d t_{A}}\left[(1+r)\left(t_{B \alpha}-t_{A \alpha}\right)+T_{B \alpha}-T_{A \alpha}\right]}{(N-m-M)+\frac{d M}{d T_{A \alpha}}\left(T_{B \alpha}-T_{A \alpha}\right)} \frac{K}{k}= \\
& =\frac{(N+m)(1+r)+\frac{d m}{d t_{A}}\left[(1+r)\left(t_{A \alpha}-t_{B \alpha}\right)+T_{A \alpha}-T_{B \alpha}\right]}{(N+m+M)+\frac{d M}{d T_{A \alpha}}\left(T_{A \alpha}-T_{B \alpha}\right)}
\end{aligned}
$$

and a solution to this equation is: $t_{i \alpha}^{f}=t_{\alpha}^{f}, T_{i \alpha}^{f}=T_{\alpha}^{f}$ for $i=A, B$, and $M^{f}=-m^{f}$ with $m^{f}$ determined by equation (39) as follows:

$$
m^{f}=N \frac{(1+\varepsilon)^{\frac{1}{1-\gamma}}-(1-\varepsilon)^{\frac{1}{1-\gamma}}}{\Omega}>0
$$

where $\Omega \equiv(1+\varepsilon)^{\frac{1}{1-\gamma}}+(1-\varepsilon)^{\frac{1}{1-\gamma}}$. Hence both the FOCs boil down to the Euler equation (42). The equilibrium conditions in the labor market give: $W_{i \alpha}=W^{*}$ (defined by equation 4 ) and $w_{i \alpha}=w^{f}$ for $i=A, B$, where:

$$
w^{f}=W^{*}\left(\frac{\Omega}{2}\right)^{1-\gamma}>W^{*}
$$

and $\Omega>2$ is obtained by applying the Jensen's inequality to the function $y=x^{\frac{1}{1-\gamma}}$. Since $W^{*}=\frac{1}{2}(\bar{w}+\underline{w})$, it is $w^{f}>\frac{1}{2}(\bar{w}+\underline{w})$.

The same reasoning applies to the state $s=\beta$, with $m^{f}<0$.

\section{Proof of Proposition 6}

Part A: it is either $t_{A s}^{n} \neq t_{B s}^{n}$ or $T_{A s}^{n} \neq T_{B s}^{n}$ or both. Consider the state $s=\alpha$, and let be $t_{i \alpha}=t_{\alpha}$ and $T_{i \alpha}=T_{\alpha}$ for $i=A, B$. Equation (18) and $T_{A \alpha}=T_{B \alpha}$ imply $M=-m$. Equation (39) and $t_{A \alpha}=t_{B \alpha}$ imply $m=m^{f}$ (defined by 51). By inserting these values of $m$ and $M$ into the national budget constraints (26) and (27), we get:

$$
\begin{aligned}
T_{A \alpha} & =-\frac{\left(N-m^{f}\right) t_{\alpha}(1+r)}{N} \\
T_{B \alpha} & =-\frac{\left(N+m^{f}\right) t_{\alpha}(1+r)}{N}
\end{aligned}
$$


which in turn imply that it must be $T_{A \alpha} \neq T_{B \alpha}$. Hence assuming that $t_{i \alpha}=t_{\alpha}$ and $T_{i \alpha}=T_{\alpha}$ for $i=A, B$ leads to a contradiction.

Part B: $m \neq m^{f}$. Let be $\delta_{A}=\delta_{B}$. Equation (39) and $m=m^{f}$ (defined in 51) imply that $t_{A \alpha}=t_{B \alpha}$. Then the condition $\frac{C_{A \alpha}^{n}}{c_{A \alpha}^{n}}=\frac{C_{B \alpha}^{n}}{c_{B \alpha}^{n}}$ becomes (after inserting equations $29-30-31$ )

$$
\frac{\left(N-m^{f}\right)}{\left(N-m^{f}-M\right)-T_{A \alpha} \frac{d M}{d T_{A \alpha}}} \frac{K}{k}=\frac{\left(N+m^{f}\right)}{\left(N+m^{f}+M\right)-T_{B \alpha} \frac{d M}{d T_{A \alpha}}}
$$

since $\frac{d m}{d t_{A \alpha}}=0$ for $t_{A \alpha}=t_{B \alpha}$. The solution to this equation is $M=-m^{f}$ and $T_{A \alpha}=T_{B \alpha}$. Hence $m=m^{f}$ implies that $t_{A \alpha}=t_{B \alpha}$ and $T_{A \alpha}=T_{B \alpha}$, but this cannot be the case, as shown in Part A.

The same reasoning (for both Parts A and B) applies to the state $s=\beta$.

\section{Appendix 2: Further results and discussion of equilibrium uniqueness}

In this Appendix, we provide some further results related to the national fiscal policies, and we discuss the issue of uniqueness of the Nash equilibrium.

We focus on country $A$ and state of the world $\alpha$; the results for country $B$ and state $\beta$ are analogous. We begin with the case of symmetric shocks. From the intertemporal budget constraint in this case:

$$
T_{A \alpha}=-\frac{(N-m) t_{A \alpha}(1+r)}{(N-m-M)} ; T_{B \alpha}=-\frac{(N+m) t_{B \alpha}(1+r)}{(N+m+M)}
$$

Substituting in the labor market equilibrium conditions for the second period,

$\Theta \gamma\left[(N-m-M)^{\gamma-1}-(N+m+M)^{\gamma-1}\right]+T_{A \alpha}-T_{B \alpha}=0$

and totally differentiating for $t_{A \alpha}$, we get the relationship between first period and second period mobility:

$$
\begin{aligned}
& \left\{\Theta \gamma(1-\gamma)\left[(N-m-M)^{\gamma-2}+(N+m+M)^{\gamma-2}\right]-\frac{(N-m) t_{A \alpha}(1+r)}{(N-m-M)^{2}}-\frac{(N+m) t_{B \alpha}(1+r)}{(N+m+M)^{2}}\right\} d M / d t_{A \alpha} \\
& -\left\{\Theta \gamma(1-\gamma)\left[(N-m-M)^{\gamma-2}+(N+m+M)^{\gamma-2}\right]-\frac{M t_{A \alpha}(1+r)}{(N-m-M)^{2}}+\frac{M t_{B \alpha}(1+r)}{(N+m+M)^{2}}\right\} d m / d t_{A \alpha}+ \\
& +\frac{(N-m)(1+r)}{(N-m-M)} \\
& \text { Manipulating the formulas we get: }
\end{aligned}
$$


$\left(^{*}\right) d M / d t_{A \alpha}=-d m / d t_{A \alpha}-A^{-1}\left(\frac{t_{A \alpha}(1+r)}{(N-m-M)}+\frac{t_{B \alpha}(1+r)}{(N+m+M)}\right) d m / d t_{A \alpha}+A^{-1} \frac{(N-m)(1+r)}{(N-m-M)}$

where $A=\frac{\left\{C_{A a}-\gamma W_{A \alpha}\right\}}{(N-m-M)}+\frac{\left\{C_{B a}-\gamma W_{B \alpha}\right\}}{(N+m+M)}>0$. Equation $\left(^{*}\right)$ shows that $d M / d t_{A \alpha}>0$, and it is larger in absolute terms than $d m / d t_{A \alpha}$. We can therefore state the following :

Lemma: i. $\operatorname{sign}\left(d M / d t_{i s}\right)=-\operatorname{sign}\left(d m / d t_{i s}\right)$ ii. $\left|d M / d t_{i s}\right|>\left|d m / d t_{i s}\right|$

Consider now consumption in the second period in country $A$ :

$$
C_{A a}=W_{A \alpha}+T_{A \alpha}=\Theta \gamma(N-m-M)^{\gamma-1}-\frac{(N-m) t_{A \alpha}(1+r)}{(N-m-M)}
$$

totally differentiating, we get:

$$
\begin{aligned}
& d C_{A a} / d t_{A \alpha}=\left\{\Theta \gamma(1-\gamma)(N-m-M)^{\gamma-2}-\frac{(N-m) t_{A \alpha}(1+r)}{(N-m-M)^{2}}\right\} d M / d t_{A \alpha}+ \\
& \left\{\Theta \gamma(1-\gamma)\left[(N-m-M)^{\gamma-2}-\frac{M t_{A \alpha}(1+r)}{(N-m-M)^{2}}\right\} d m / d t_{A \alpha}-\frac{(N-m)(1+r)}{(N-m-M)}\right.
\end{aligned}
$$

which can be rewritten, by manipulating the formulas, as

$$
d C_{A a} / d t_{A \alpha}=B d M / d t_{A \alpha}+\left\{B+\frac{t_{A \alpha}(1+r)}{(N-m-M)}\right\} d m / d t_{A \alpha}-\frac{(N-m)(1+r)}{(N-m-M)}
$$
get

where $B=\frac{\left\{C_{A a}-\gamma W_{A \alpha}\right\}}{(N-m-M)}$. Substituting for $d M / d t_{A \alpha}$ from $\left(^{*}\right)$, we finally

$$
\begin{aligned}
& \left.(* *) d C_{A a} / d t_{A \alpha}=(1+r)\left\{\frac{t_{A \alpha}}{(N-m-M)}\left(1-B A^{-1}\right)-B A^{-1} \frac{t_{B \alpha}}{(N+m+M)}\right)\right\} d m / d t_{A \alpha}- \\
& \frac{(N-m)(1+r)}{(N-m-M)}\left(1-B A^{-1}\right) \\
& \text { We are then able to state the following: }
\end{aligned}
$$

Proposition 7 . For $m=0, d C_{A a} / d t_{A \alpha}=\frac{-(1+r)}{2}$. ii. For $m \neq 0$, but not "too" large, $d C_{i a} / d t_{i \alpha}<0$ and $d^{2} C_{i a} / d t_{i \alpha}^{2}<0$.iii. For $m \neq 0$ and large, sign $d C_{i a} / d t_{i \alpha}$ uncertain.

Note that $B A^{-1}<1$. The second term is then certainly negative while the sign of the first depends on the difference between the two tax rates. At $t_{A \alpha}=t_{B \alpha}$ (that implies $\left.m=M=0\right), B A^{-1}=1 / 2$ and the first term is zero. At $t_{A \alpha}>(<) t_{B \alpha}$ the first term is negative (positive). By continuity, this term is however small and dominated by the second for $m$ small, that is, as long as the two tax rates are not too different. Hence, $d C_{A a} / d t_{A \alpha}<0$ for all $t_{A \alpha} \geq t_{B \alpha}$ and it is still negative for $t_{A \alpha}<t_{B \alpha}$ provided that 
$t_{B \alpha}$ is not too larger than $t_{A \alpha}$. Intuitively, if $t_{A \alpha} \geq t_{B \alpha}$, increasingly further $t_{A \alpha}$ implies a higher cost in terms of second period consumption for country $A$. If $t_{A \alpha}<t_{B \alpha}$ this cost is lower, and possibly, if $t_{B \alpha}$ is much higher than $t_{A \alpha}$, the cost might even become negative. Finally, note that at $t_{A \alpha}=t_{B \alpha}$, $d C_{A a} / d t_{A \alpha}=\frac{-(1+r)}{2}$.

Recalling the definition of $\frac{d m}{d t_{A \alpha}}$ from Proposition 1, it can be proved that $\frac{d^{2} m}{d t_{A \alpha}^{2}}=0$ for $m=0$ and $\frac{d^{2} m}{d t_{A \alpha}^{2}}<(>) 0$ for $m<(>) 0$. Using this fact, and differentiating again (**), one gets that $d^{2} C_{A a} / d t_{A \alpha}^{2}<0$ for $t_{A \alpha} \geq t_{B \alpha}$; for $t_{A \alpha}<t_{B \alpha}$ the sign is uncertain, but it is negative by continuity for $t_{B \alpha}$ not too larger than $t_{A \alpha}$, for the same reasons already discussed above. Finally, $d^{2} C_{A a} / d t_{A \alpha} d t_{B \alpha}>0$ under the same conditions.

\section{Convexity of the government's problem}

Consider again government $A^{\prime} s$ problem in state $\alpha$ in the case of symmetric shocks. Government $\max F^{A}=\ln \left(c_{A a}\right)+\delta_{A} \ln \left(C_{A a}\right)$, where all mobility and budget constraints are directly substituted in the objective function. The FOC for this problem, invoking Proposition 1 and the above, can be written as:

$$
d F^{A} / d t_{A \alpha}=\frac{1}{c_{A a}} \frac{k}{1+k}+\frac{\delta_{A}}{C_{A a}} d C_{A a} / d t_{A \alpha}=0
$$

where $k \equiv\left(\frac{N+m}{N-m}\right)^{\gamma-2}$ and $d C_{A a} / d t_{A \alpha}$ is given by the equation (**) above. Clearly, $d C_{A a} / d t_{A \alpha}$ must be negative for this equation to hold. If $d C_{A a} / d t_{A \alpha}>$ 0 , that as we showed above can however only happen for $t_{B \alpha}$ much larger than $t_{A \alpha}$, the best solution for government $A$ would be to keep increasing $t_{A \alpha}$ up to the point in which $d C_{A a} / d t_{A \alpha}$ becomes negative and equal the first term. Hence, the equation above certainly characterizes government behavior. The equation defines a (local) maximum if the SOC are also satisfied. Taking the second derivative:

$$
\begin{aligned}
& d^{2} F^{A} / d t_{A \alpha}^{2}=-\frac{1}{\left(c_{A a}\right)^{2}}\left(\frac{k}{1+k}\right)^{2}-\frac{\delta_{A}}{\left(C_{A a}\right)^{2}}\left(d C_{A a} / d t_{A \alpha}\right)^{2}+\frac{\delta_{A}}{C_{A a}} d^{2} C_{A a} / d t_{A \alpha}^{2}- \\
& \frac{1}{c_{A a}} \frac{k}{(1+k)^{2}} \frac{2 N(2-\gamma)}{(N+m)(N-m)} d m / d t_{A \alpha} \\
& \text { the first two terms are certainly negative, the third is negative under the }
\end{aligned}
$$
conditions stated above, and the fourth is certainly positive as $d m / d t_{A \alpha}<0$. The sign is therefore uncertain. Notice however that for $m$ close to zero, the fourth term is certainly dominated by the first, so that $d^{2} F^{A} / d t_{A \alpha}^{2}<0$. By continuity, then the SOC are certainly satisfied if $m$ is not too large, that 
means that the two tax rates cannot be two far one from the others and that the parameter determining the elasticity of $m$ to tax rate differentials, $\gamma$, must be close to $1 / 2$.

\section{Nash equilibria}

Assuming the SOC is satisfied, the FOC above identifies the optimal choice of $t_{A \alpha}, t_{A \alpha}^{*}$. In particular, we have the identity:

$d F^{A} / d t_{A \alpha}\left(t_{A \alpha}^{*} ; t_{B \alpha}\right) \equiv 0$, where $t_{B \alpha}$ is the tax choice by country B. Totally differentiating:

$$
d t_{A \alpha}^{*} / d t_{B \alpha}=-\frac{d^{2} F^{A} / d t_{A \alpha} d t_{B \alpha}}{d^{2} F^{A} / d t_{A \alpha}^{2}}
$$

thus $\operatorname{sign}\left(d t_{A \alpha}^{*} / d t_{B \alpha}\right)=\operatorname{sign}\left(d^{2} F^{A} / d t_{A \alpha} d t_{B \alpha}\right)$, as $d^{2} F^{A} / d t_{A \alpha}^{2}<0$. Computing:

$$
\begin{aligned}
& d^{2} F^{A} / d t_{A \alpha} d t_{B \alpha}= \\
& -\frac{1}{\left(c_{A a}\right)^{2}}\left(\frac{k}{1+k}\right)^{2}-\frac{\delta_{A}}{\left(C_{A a}\right)^{2}}\left(d C_{A a} / d t_{A \alpha}\right)^{2}+\frac{\delta_{A}}{C_{A a}} d^{2} C_{A a} / d t_{A \alpha} d t_{B a}-\frac{1}{c_{A a}} \frac{k}{(1+k)^{2}} \frac{2 N(2-\gamma)}{(N+m)(N-m)} d m / d t_{B \alpha}
\end{aligned}
$$

The first two elements derive by perfect mobility (see proposition 1); an increase in $t_{B \alpha}$ have the same effect on $c_{A a}$ than an increase in $t_{A \alpha}$; similarly for $C_{A a}$. The third element is positive, under the conditions stated above, the fourth is negative (as $d m / d t_{B \alpha}>0$ ). Hence, unless the third element is very large, the reaction function is negatively sloped; that is, a higher $t_{B \alpha}$ would reduce $t_{A \alpha}^{*}$.

Notice further that as long as the problem of the govern is well behaved, the reaction functions are continuous and map a compact set in itself. Hence a Nash equilibrium in the first period tax rates surely exists. Uniqueness would also follow if each reaction function were a contraction in the tax rates. That is, provided that

$$
d t_{A \alpha}^{*} / d t_{B \alpha}=\left|-\frac{d^{2} F^{A} / d t_{A \alpha} d t_{B \alpha}}{d^{2} F^{A} / d t_{A \alpha}^{2}}\right|<1
$$

Computing, this condition can be written as

$$
\frac{\delta_{A}}{C_{A a}} d^{2} C_{A a} / d t_{A \alpha} d t_{B a}-\frac{\delta_{A}}{C_{A a}} d^{2} C_{A a} / d t_{A \alpha}^{2}>-\frac{2}{c_{A a}} \frac{k}{(1+k)^{2}} \frac{2 N(2-\gamma)}{(N+m)(N-m)} d m / d t_{A \alpha}
$$

The terms on both the RHS and the LHS are positive under the conditions stated above; but the complexity of the formulas do not allow us to determine if this condition is satisfied or not. Hence we cannot rule out the existence of multiple Nash equilibrium. 
Consider now the case with asymmetric shocks. Here, mobility in the first period also depend on the realization of the shock; workers in the first period now move even if $t_{A \alpha}=t_{B \alpha}$. Let $m=m^{*}$ and the corresponding $M^{*}$ be workers' mobility with identical taxation. But what matters for the governments' problem to be well behaved and for the existence of the equilibrium is the additional mobility generated by the difference in the tax rates. This still depends by the functions we discussed above, just substituting in the formula for $m^{*}$ and $M^{*}$ when $t_{A \alpha}=t_{B \alpha}$ and reinterpreting $m$ as variation with respect to $m^{*}$. With this sostitution, and reintepreting $k$ as discussed in the text for the case of asymmetric shock, our analysis in this Appendix still holds.

\section{References}

Belke A, D. Gros, (2009a), "Is a unified macroeconomic policy necessarily better for a common currency area?", European Journal of Political Economy, 25: 98-101.

Belke A, D. Gros, (2009b), "On the benefits of fiscal policy coordination in a currency union: a note", Empirica, 36: 45-49.

Bofinger P., E. Mayer (2007), "Monetary and fiscal policy interaction in the Euro area with different assumptions on the Phillips curve", Open Economy Review, 18: 291-305.

Canzoneri M., V. Grilli, P. Masson (1991), Establishing a Central Bank: Issues in Europe and Lessons from the US, Cambridge, Cambridge University Press.

Commission of the European Communities (1977), Report of the Study Group on the Role of Public Finance in European Integration, vol. 1: General Report, Brussels, April 1977.

Delors J. (1989), "Regional implications of economic and monetary integration", in Committee for the Study of Economic and Monetary Union, Report on Economic and Monetary Union in the European Community, Luxembourg, Office for Official Publications of the EC.

Evers M.P. (2006), "Federal fiscal transfers in monetary unions: a NOEM approach", International Tax and Public Finance, 13: 463-488.

Fair D., C. de Boissieux, eds (1992), Fiscal Policy, Taxes, and the Financial System in an Increasingly Integrated Europe, Deventer, Kluwer. 
Hairault J.O., P.Y. Henin, F. Portier, eds. (1997), Should We Rebuild Built-in Stabilizers, Dodrecht, Kluwer.

Hughes-Hallet A., M. Hutchison, S. Jensen, eds. (1999), Fiscal Aspects of European Monetary Integration, Cambridge, Cambridge University Press.

Jonung L., E.Drea (2009), "The euro: it can't happen. It's a bad idea. It won't last. US economists on the EMU, 1989-2002", European Economy, Economic Papers 395/ December 2009.

Kenen P. (1969), "The theory of optimum currency areas: an eclectic view", in Mundell, Swoboda, eds. (1969).

Kletzer K. (1999), "Monetary union, asymmetric productivity shocks and fiscal insurance: an analytical discussion of welfare issues", in Hughes-Hallet, Hutchison, Jensen, eds. (1999).

Kletzer K., W. Buiter (1997), "Monetary union and the role of automatic stabilizers", in Hairault, Henin, Portier, eds. (1997).

Kletzer K. J. von Hagen (2001), "Monetary union and fiscal federalism", in Wyplosz, ed. (2001).

Maćkowiak B., F.P. Mongelli, G. Noblet, F. Smets (2008), The Euro at Ten - Lesson and Challenges, Frankfurt am mein, ECB.

Mundell R. (1961), "A theory of optimum currency areas", American Economic Review, 51: 657-665.

Mundell R., A. Swoboda, eds. (1969), Monetary Problems of the International Economy, University of Chicago Press.

Sala-i-Martin X., J. Sachs (1991), "Fiscal federalism and optimum currency areas: evidence for Europe from the United States", in Canzoneri, Grilli, Masson, eds. (1991).

Sapir A. (2004), An Agenda for a Growing Europe, New York, Oxford University Press.

Sapir (2008), "The OCA theory", in Maćkowiak, Mongelli, Noblet, Smets (2008), 264-267.

von Hagen J. (1992), "Fiscal arrangements in a monetary union: some evidence from the US", in Fair, de Boissieux, eds. (1992).

von Hagen J., C. Wyplosz (2008), "EMU's decentralized system of fiscal policy", European Economy, Economic Papers 306/February 2008.

Wyplosz C., ed. (2001), The Impact of EMU on europe and the Developing Countries, Oxford, Oxford University Press. 
1. L. Colombo, H. Dawid, Strategic Location Choice under Dynamic Oligopolistic Competition and Spillovers, Novembre 2013.

2. M. Bordignon, M. Gamalerio, G. Turati, Decentralization, Vertical Fiscal Imbalance, and Political Selection, Novembre 2013.

3. M. Guerini, Is the Friedman Rule Stabilizing? Some Unpleasant Results in a Heterogeneous Expectations Framework, Novembre 2013.

4. E. Brenna, C. Di Novi, Is caring for elderly parents detrimental to women's mental health? The influence of the European North-South gradient, Novembre 2013.

5. F. Sobbrio, Citizen-Editors' Endogenous Information Acquisition and News Accuracy, Novembre 2013.

6. P. Bingley, L. Cappellari, Correlation of Brothers Earnings and Intergenerational Transmission, Novembre 2013.

7. T. Assenza, W. A. Brock, C. H. Hommes, Animal Spirits, Heterogeneous Expectations and the Emergence of Booms and Busts, Dicembre 2013.

8. D. Parisi, Is There Room for 'Fear' as a Human Passion in the Work by Adam Smith?, Gennaio 2014.

9. E. Brenna, F. Spandonaro, Does federalism induce patients' mobility across regions? Evidence from the Italian experience, Febbraio 2014.

10. A. Monticini, F. Ravazzolo, Forecasting the intraday market price of money, Febbraio 2014.

11. Tiziana Assenza, Jakob Grazzini, Cars Hommes, Domenico Massaro, $P Q$ Strategies in Monopolistic Competition: Some Insights from the Lab, Marzo 2014.

12. R. Davidson, A. Monticini, Heteroskedasticity-and-Autocorrelation-Consistent Bootstrapping, Marzo 2014.

13. C. Lucifora, S. Moriconi, Policy Myopia and Labour Market Institutions, Giugno 2014.

14. N. Pecora, A. Spelta, Shareholding Network in the Euro Area Banking Market, Giugno 2014.

15. G. Mazzolini, The economic consequences of accidents at work, Giugno 2014.

16. M. Ambrosanio, P. Balduzzi, M. Bordignon, Economic crisis and fiscal federalism in Italy, Settembre 2014.

17. P. Bingley, L. Cappellari, K. Tatsiramos, Family, Community and Long-Term Earnings Inequality, Ottobre 2014.

18. S. Frazzoni, M. L. Mancusi, Z. Rotondi, M. Sobrero, A. Vezzulli, Innovation and export in SMEs: the role of relationship banking, Novembre 2014.

19. H. Gnutzmann, Price Discrimination in Asymmetric Industries: Implications for Competition and Welfare, Novembre 2014.

20. A. Baglioni, A. Boitani, M. Bordignon, Labor mobility and fiscal policy in a currency union, Novembre 2014. 